\title{
PENGARUH PENGGUNAAN FILM DOKUMENTER PROKLAMASI TERHADAP KETERAMPILAN BERFIKIR KRITIS DAN HASIL BELAJAR PADA PEMBELAJARAN IPS SISWA KELAS IX SMP 2 ABIANSEMAL
}

\author{
Louis Edward Gero', Nengah Bawa Atmaja ${ }^{2}$, I Putu Sriartha ${ }^{3}$ \\ Prodi Pendidikan IPSUniversitas Pendidikan Ganesha Singaraja \\ e-mail: louiseedward17@gmail.com ${ }^{1}$
}

\begin{abstract}
Abstrak
Tujuan penelitian ini untuk mengetahui (1) pengaruh secara simultan film dokumenter proklmasi terhadap hasil belajar dan berfikir kritis siswa kelas IX SMPN 2 ABIANSEMAL, (2) pengaruh penggunaan film dokumenter proklamasi terhadap hasil belajar dan (3) pengaruh pengunaan film dokumenter proklamasi terhadap berfikir kritis siswa.Penelitian menggunakan metode Eksperimen dan Eksperiment Validation. Populasi penelitian ini adalah seluruh kelas IX dengan sampel kelas IX B dan IX Dyang ditentukan dengan teknik Random sampling. Pengumpulan data menggunakan teknik tes objektif dan esaay .Uji hipotesis menggunakan uji-F dan uji Manova.Hasil penelitian menunjukkan bahwa (1) ada pengaruh film dokumenter proklmasi terhadap keterampilan berfikir kritis dan hasil belajar siswa kelas ix SMPN 2 Abiansemal, (2) ada pengaruh film dokumenter proklmasi terhadap keterampilan berfikir kritis siswa kelas ix SMPN 2 Abiansemal, (3) ada pengaruh film dokumenter proklamasi terhadap hasil belajar siswa kelas ix SMPN 2 Abiansemal.
\end{abstract}

Kata Kunci: Film dokumenter, hasil belajar , keterampilan berpikir kritis

\begin{abstract}
Abstrack
The purpose of this study is to find out (1) the simultaneous influence of documentary documentary film on the results of critical learning and thinking of class IX students of SMP 2 ABIANSEMAL, (2) the influence of the use of documentary proclamation on learning outcomes and (3) the effect of proclamation documentary on critical thinking students. Research uses the Experiment and Validation Experiment method. The population of this study was all class IX with samples of class IX B and IX D determined by Random sampling technique. Data collection uses objective and esa test techniques. Hypothesis testing using F-test and Manova test. The results showed that (1) there was the influence of the documentary filmmaking on critical thinking skills and the learning outcomes of class IX students of Abiansemal Junior High School, (2) there was the influence of the documentary filmmaking on the critical thinking skills of class students in SMP 2 Abiansemal, (3) influence documentary proclamation of the learning outcomes of class ix students of SMP 2 Abiansemal.
\end{abstract}

Keywords: Documentary films, learning outcomes, critical thinking skills

\section{Pendahuluan}

Perkembangan ilmu pengetahuan dan teknologi semakin mendorong upaya-upaya pembaharuan dalam pemanfaatan hasil-hasil teknologi dalam proses belajar mengajar. Para guru dituntut agar mampu mempuyai, menerapakan dan menggunakan alat-alat yang dapat disediakan oleh sekolah, dan tidak menutup kemungkinan bahwa alat-alat tersebut sesuai dengan perkembangan dan tuntutan zaman yaitu dalam bidang teknolgi khususnya dalam bentuk media film. Media sebagai salah satu komponen dari pengajaran yang sangat berpengaruh terhadap proses pembelajaran. Dengan adanya media pembelajaran diharapkan mampu meningkatkan kualitas hasil belajar siswa. Media pembelajaran digunakan sebagai saluran untuk menyampaikan materi dari guru kepada siswa. Dengan adanya media yang 
mendukung proses pembelajaran, akan mampu meningkatkan hasil belajar siswa. Media pembelajaran juga dianggap efektif untuk meningkatkan motivasi belajar siswa sehingga dapat meningkatkan hasil belajar siswa. Menurut Santoso S. Hamijaya (dalam Ahmad Rohani, 1997:2) media merupakan semua bentuk perantara yang dipakai orang penyebar ide, sehingga ide atau gagasan itu sampai pada penerima.Media merupakan salah satu komponen pengajaran yang sangat berpengaruh terhadap proses pembelajaran. Pembelajaran kontekstual adalah suatu konsep belajar yang membantu guru mengaitkan antara materi yang diajarkannya dengan situasi dunia nyata siswa, dan mendorong siswa membuat hubungan antara pengetahuan yang dimilikinya dengan penerapannya dalam kehidupan sehari-hari sebagai anggota keluarga dan masyarakat. Melalui implementasi tujuh komponen pembelajaran kontekstual (contextual teaching and learning) siswa akan lebih memaknai dan mamahami materi pembelajaran, sehingga apa yang telah diperoleh di sekolah dapat diimplementasikan di lingkungannya. Dan dapat menembangkan semua konsep-konsep audio visual seperti video ,agar memeudahkan siswa mengerti dan dapat menjelaskan apa saja peristiwa yang ada di vidio tersebut, serta dapat memahami isi dari dalam film dokumenter proklamasi. Film dokumenter adalah jenis film non fiksi yang mengandung fakta peristiwa serta sikap atau opini dari pembuat film dokumenter fakta peristiwa dapat diceritakan (Masseli Sumarno, 1996:4). Film dokumenter berisikan rekaman segala sesuatu sesuai dengan apa yang dilihat, biasanya berisikan peristiwa penting yang diperkirakan tidak akan terulang kembali. Film dokumenter dibuat dengan perhitungan matang dengan diseleksi, memperhitungkan credit title (daftar para pembuat film), dapat berkisah tentang sejarah, satwa, atau peristiwa yang berkaitan dengan kegiatan upacara tradisi dan upacara resmi. Semunya dibuat menurut kebutuhan si pembuat film. Menurut Onong Uchjana Efendi (1989 : 160), unsur film dokumenter yakni : (1) Peristiwa benar benar terjadi/ faktual; (2) Materi melalui pengamatan langsung; (3) Kejadian masa lampau : (4) Berkaitan dengan ilmu pengetahuan. Sedangkan ciri-ciri film dokumenter : (1) Waktu penayangan singkat; (2) Problem yang terjadi di masyarakat; (3) Bukan cerita bersambung; (4) Tidak bercerita tentang percintaan. Film dokumenter menyajikan realita melalui berbagai cara dan dibuat untuk tujuan tertentu, seperti penyebaran informasi, kepada individu maupun kelompok. Misalnya film dokumenter dapat dijadikan alat komunikasi antar masyarakat, individu bahkan bangsa, yang tempat tinggalnya jauh terpencil. Di samping itu juga menambah pengetahuan misalnya kehidupan satwa langka yang buas dan sulit diketemukan karena Dalam menerapkan dan menugimplementasikan komponen-komponen pembelajaran kontekstual harus mempertimbangkan materi pembelajaran, sarana pendukung, dan kompetensi apa yang harus dimiliki oleh siswa dan siswa harus mencermati dan mengamati. Misalnya penggunaan komponen pemodelan (modeling) pada mata pelajaran Pendidikan Kewarganegaraan untuk materi Proklamasi Kemerdekaan diperlukan model atau saksi sejarah yang bisa menjelaskan secara langsung bagaimana suasana kebatinan, beratnya perjuangan untuk memperoleh dan mempertahankan kemerdekaan, rasa kebangsaan dan nasionalisme yang sebenarnya terjadi pada masa itu. Sementara itu untuk media audivisiual berarti dapat dilihat sekaligus di dengar. Salah satu jenis medjadi sekitar Proklamasi Kemerdekaan RI langsung dari pelaku sejarah. Dalam penelitian hasil belajar siswa rata- rata kurang maksimal di karenakan kurangnya semangat siswa untuk belajar karena dalam metode pelajaran mendengar penjelaasan mereka cukup bosan ,sehingga hasil belajar siswa sedikit rendah. Sehingga kita harus dapat menganti metode pembelajaran terutama dalam pembelajran ips memngunakan media film yaitu film dokumenter proklamasi agar siswa tidak bosan dengan metode pembelajaran yang sebelumnya di gunakan. Dan dapat meningkatkan hasil belajar siswa di SMP 2 Abiansemal.

\section{Metode}

Penelitian ini menggunakan metode eksperimen.Metode eksperimen merupakanmetode penelitian yang digunakan untuk mencari pengaruh, dengan memberikan treatment (perlakuan) 
tertentu. Eksperimen bersifat validation atau menguji pengaruhsatu atau lebih variabel terhadap variabel lain. Variabel-variabel yang ada termasukvariabel bebas atau independent variable dan variabel terikat atau dependent variable,sudah ditentukan secara tegas oleh para peneliti (Sukardi, 2008: 178).

Dalampenelitian dibedakan 2 kelompok, yaitu kelompok yang dalam pembelajaran tidakmenggunakan media fillm dokumenter proklamasi dengan pembelajaran yangmenggunakan media film dokumenter proklamasi. Variabel bebas terdiri atas variablemedia film dokumenter dengan variabel terikat hasil belajar IPS dan keterampilan berpikir kritis.

Pada tabel 3.1 dapat dijelaskan bahwa A1 perlakuan yang diberikan kepada kelas eksperimen dengan media fillm dokumenter proklamasi, A2 perlakuan yang diberikan kepada kelas kontrol dengan tidakmenggunakan media fillm dokumenter proklamasi, O1 adalah tes akhir yang diberikan kepada kelas eksperimen, dan $\mathrm{O} 2$ adalah tes akhir yang diberikan kepada kelas kontrol.Perbedaan perlakuan antar kelompok eksperimen dan kelompok kontrol dapat dilihat dari kegiatan guru dan siswa pada masing - masing pembelajaran sesuai dengan sintaks pembelajaran. Berdasarkan sintaks pembelajaran tersebut disusun rencana kegiatan pembelajaran yang akan diterapkan pada kelas eksperimen dan kelas control. Penelitian ini, terdiri dari satu variabel bebas yaitu penayangan film dokumenter.Dua variabel terikat yaitu hasil belajar IPS dan kemampuan berpikir kritis.Dalam penelitian inimenggunakan rancangan faktorial 2x2. Variabel bebas pertama yaitu pembelajaran sejarah menggunakan media film dokumenter Proklmasi.

\section{Hasil dan pembahasan}

Penelitian ini dilakukan pada siswa kelas IX SMP Negeri 2 Abiansemal, yang terletak di Kecamatan Abiansemal, Kabupaten Badung.Penelitian ini dilaksanakan mulai bulan Oktober sampai dengan November 2018, mulai dari penyusunan proposal sampai penyusunan laporan penelitian.Penelitian ini menggunakan metode eksperimen.Metode eksperimen merupakanmetode penelitian yang digunakan untuk mencari pengaruh, dengan memberikantreatment (perlakuan) tertentu. Eksperimen bersifat validation atau menguji pengaruhsatu atau lebih variabel terhadap variabel lain. Variabel-variabel yang ada termasukvariabel bebas atau independent variable dan variabel terikat atau dependent variable,sudah ditentukan secara tegas oleh para peneliti (Sukardi, 2008: 178). Dalampenelitian dibedakan 2 kelompok, yaitu kelompok yang dalam pembelajaran tidakmenggunakan media fillm dokumenter proklamasi dengan pembelajaran yangmenggunakan media film dokumenter proklamasi. Variabel bebas terdiri atas variabel media film dokumenter dan berfikir kritis siswa dengan variabel terikat hasil belajarIPS siswa.

\section{Tabel 1.Rekapitulasi Hasil Perhitungan Skor Hasil Belajar IPS dan Kemampuan Berpikir} Kritis

\begin{tabular}{|l|l|l|l|l|}
\hline & $\begin{array}{l}\text { Hasil Belajar } \\
\text { IPS } \\
\text { Kelompok } \\
\text { Eksperimen }\end{array}$ & $\begin{array}{l}\text { Hasil Belajar } \\
\text { IPS } \\
\text { Kelompok } \\
\text { Kontrol }\end{array}$ & $\begin{array}{c}\text { Kemampuan } \\
\text { Berpikir Kritis } \\
\text { Kelompok } \\
\text { Eksperimen }\end{array}$ & $\begin{array}{l}\text { Kemampuan } \\
\text { Berpikir Kritis } \\
\text { Kelompok } \\
\text { Kontrol }\end{array}$ \\
\hline N Valid & 32 & 34 & 32 & 34 \\
Mean & 0 & 0 & 0 & 0 \\
Median & 77.1250 & 64.8235 & 81.7500 & 68.3529 \\
Mode & 78.0000 & 68.0000 & 80.0000 & 68.0000 \\
Std. Deviation & 68.00 & 72.00 & 100.00 & 72.00 \\
Variance & 12.73995 & 14.76374 & 12.48225 & 10.29823 \\
& 162.306 & 217.968 & 155.806 & 106.053
\end{tabular}


PIPS, Vol. 2 No. 2, Bulan OktoberTahun 2018

\begin{tabular}{|l|l|l|l|l|} 
Range & 40.00 & 52.00 & 48.00 & 44.00 \\
Minimum & 56.00 & 36.00 & 52.00 & 44.00 \\
Maximum & 96.00 & 88.00 & 100.00 & 88.00 \\
\hline
\end{tabular}

Sesuai dengan analisis di atas, rata-rata skor data hasil belajar IPS yang mengikuti pembelajaran dengan film dokumenter proklamasi adalah 77,125 berada pada interval $X \geq 75$. Sehingga berdasarkan tabel klasifikasi yang telah dibuat, diketahui bahwa data-data hasil belajar IPS siswa yang mengikuti pembelajaran dengan film dokumenter proklamasi termasuk pada klasifikasi sangat tinggi.

\section{Uji Normalitas Sebaran Data}

Uji normalitas sebaran data dilakukan dengan menggunakan statistik Kolmogorov-smirnov. Kriteria pengujiannya adalah data memiliki sebaran normal jika angka signifikan yang diperoleh lebih besar dari 0,05 dan dalam hal lain data tidak berdistribusi normal. Teknik analisis dilakukan dengan bantuan SPSS 23.0 for windows. Adapun ringkasan hasil analisis uji normalitas sebaran data hasil belajar IPS dan kemampuan berpikir kritis disajikan

\section{Uji Homogenitas Varians}

Uji homogenitas varians antar kelompok ini dapat dilakukan dengan menggunakan statistik levene. Kriteria pengujian yang digunakan adalah data yang memiliki varians yang sama (homogen) jika angka signifikansi yang dihasilkan lebih besar dari 0,05. Uji homogenitas ini menggunakan nilai statistik menggunakan uji Levene, hasil uji homogenitas berdasarkan pendekatan model pembelajaran yang diterapkan

\section{Uji Homogenitas Matriks Varians}

Uji homogenitas matriks varian-kovarians antar variabel dependen menggunakan Box's Test Equality Covariance Matrices dengan bantuan program SPSS 23.0 for windows. Uji homogenitas dilakukan terhadap kelompok data hasil belajar IPS dan kemampuan berpikir kritis siswa secara bersama-sama menggunakan uji Box's $M$. Adapun ringkasan hasil uji homogenitas matriks varians-kovarians

Tabel 2. Ringkasan Hasil Analisis Uji Normalitas Data Hasil Belajar IPS dan Kemampuan Berpikir Kritis Siswa

\begin{tabular}{|l|l|l|l|l|}
\hline \multirow{2}{*}{ Perlakuan } & \multicolumn{3}{|l|}{ Kolmogorov-Smirnov } \\
\cline { 3 - 6 } Hasil belajar IPS & $\begin{array}{l}\text { Pembelajaran dengan } \\
\text { film dokumenter } \\
\text { proklamasi }\end{array}$ & .138 & 32 & .126 \\
\cline { 2 - 6 } & $\begin{array}{l}\text { Pembelajaran } \\
\text { Konvensional }\end{array}$ & .128 & 34 & .175 \\
\hline Kemampuan Berpikir Kritis & $\begin{array}{l}\text { Pembelajaran dengan } \\
\text { film dokumenter } \\
\text { proklamasi }\end{array}$ & .116 & 32 & $.200^{*}$ \\
\cline { 2 - 6 } & $\begin{array}{l}\text { Pembelajaran } \\
\text { Konvensional }\end{array}$ & .109 & 34 & $.200^{*}$ \\
\hline
\end{tabular}

\section{Uji hipotesis pertama}

Hipotesis yang diuji yaitu Ho, di mana kriteria menyatakan bahwa Ho ditolak apabila taraf signifikansi untuk Pillai's Trace, Wilk's Lambda, Hotelling's Trace, dan Roy's Largest Root lebih kecil dari 0,05. Berdasarkan Tabel 4.10 diperoleh angka 
statistik F sama dengan 17,315 dan angka signifikansi 0,000 kurang dari 0,05 untuk Pillai's Trace, Wilk's Lambda, Hotelling's Trace, dan Roy's Largest Root.Jadi hipotesis null (Ho) ditolak dan dapat disimpulkan bahwa terdapat perbedaan hasil belajar IPS dan kemampuan berpikir kritis siswa antara kelompok siswa yang belajar dengan film dokumenter proklamasi dengan kelompok siswa yang belajar dengan pembelajaran konvensional.

Dalam pengujian hipotesis yang kedua dan ketiga dapat dilihat pada hasil analysis test of between-subjects effects. Hasil analisis tersebut menampilkan nilai signifikansi untuk masingmasing unit analisis yaitu untuk data hasil belajar IPS dan kemampuan berpikir kritis.

Tabel 3. Tests of Between-Subjects Effects

\begin{tabular}{|c|c|c|c|c|c|c|}
\hline Source & Dependent Variable & $\begin{array}{l}\text { Type III Sum } \\
\text { of Squares }\end{array}$ & df & Mean Square & $\mathrm{F}$ & Sig. \\
\hline \multirow{2}{*}{$\begin{array}{l}\text { Corrected } \\
\text { Model }\end{array}$} & Hasil Belajar IPS & $2494.589^{a}$ & 1 & 2494.589 & 13.060 & .001 \\
\hline & $\begin{array}{l}\text { Kemampuan Berpikir } \\
\text { Kritis }\end{array}$ & $2958.720^{b}$ & 1 & 2958.720 & 22.733 & .000 \\
\hline \multirow[t]{2}{*}{ Intercept } & \multirow{2}{*}{$\begin{array}{l}\text { Hasil Belajar IPS } \\
\text { Kemampuan Berpikir } \\
\text { Kritis }\end{array}$} & 332159.559 & 1 & 332159.559 & 1738.993 & .000 \\
\hline & & 371418.357 & 1 & 371418.357 & 2853.715 & .000 \\
\hline \multirow[t]{2}{*}{ Kelas } & \multirow{2}{*}{$\begin{array}{l}\text { Hasil Belajar IPS } \\
\text { Kemampuan Berpikir } \\
\text { Kritis }\end{array}$} & 2494.589 & 1 & 2494.589 & 13.060 & .001 \\
\hline & & 2958.720 & 1 & 2958.720 & 22.733 & .000 \\
\hline \multirow[t]{2}{*}{ Error } & \multirow{2}{*}{$\begin{array}{l}\text { Hasil Belajar IPS } \\
\text { Kemampuan Berpikir } \\
\text { Kritis }\end{array}$} & 12224.441 & 64 & 191.007 & & \\
\hline & & 8329.765 & 64 & 130.153 & & \\
\hline \multirow[t]{2}{*}{ Total } & \multirow{2}{*}{$\begin{array}{l}\text { Hasil Belajar IPS } \\
\text { Kemampuan Berpikir } \\
\text { Kritis }\end{array}$} & 345440.000 & 66 & & & \\
\hline & & 381040.000 & 66 & & & \\
\hline \multirow{2}{*}{$\begin{array}{l}\text { Corrected } \\
\text { Total }\end{array}$} & \multirow{2}{*}{$\begin{array}{l}\text { Hasil Belajar IPS } \\
\text { Kemampuan Berpikir } \\
\text { Kritis }\end{array}$} & 14719.030 & 65 & & & \\
\hline & & 11288.485 & 65 & & & \\
\hline
\end{tabular}

a. $\mathrm{R}$ Squared $=.169$ (Adjusted $\mathrm{R}$ Squared $=.157$ )

b. R Squared $=.262$ (Adjusted R Squared $=.251$ )

Tabel 4.Ringkasan Uji MultivariateMultivariate Tests ${ }^{a}$

\begin{tabular}{|ll|l|l|l|l|l|}
\hline Effect & Value & F & $\begin{array}{l}\text { Hypothesis } \\
\text { df }\end{array}$ & Error df & Sig. \\
\hline Intercept & Pillai's Trace & .986 & $2221.411^{\mathrm{b}}$ & 2.000 & 63.000 & .000 \\
& Wilks' Lambda & .014 & $2221.411^{\mathrm{b}}$ & 2.000 & 63.000 & .000 \\
& Hotelling's Trace & 70.521 & $2221.411^{\mathrm{b}}$ & 2.000 & 63.000 & .000 \\
& Roy's Largest & 70.521 & $2221.411^{\mathrm{b}}$ & 2.000 & 63.000 & .000 \\
\hline Root & .355 & $17.315^{\mathrm{b}}$ & 2.000 & 63.000 & .000 \\
& Relas & Pillai's Trace & $17.315^{\mathrm{b}}$ & 2.000 & 63.000 & .000 \\
& Wilks' Lambda & .645 & $17.315^{\mathrm{b}}$ & 2.000 & 63.000 & .000 \\
& Hotelling's Trace & .550 & $17.315^{\mathrm{b}}$ & 2.000 & 63.000 & .000 \\
& Roy's Largest & .550 & & & & \\
\hline
\end{tabular}




\section{Uji hipotesis kedua}

Hipotesis 2 yang diuji dengan test of between-subjects effects yaitu Ho, di mana kriteria menyatakan bahwa Ho ditolak apabila taraf signifikansi $F$ lebih kecil dari 0,05. Berdasarkan Tabel 4.11 diperoleh angka statistik $F$ sama dengan 13,060 dan angka sig. 0,001<0,05. Jadi hipotesis null (Ho) ditolak dan dapat disimpulkan bahwa terdapat perbedaan hasil belajar IPS siswa antara kelompok siswa yang belajar dengan film dokumenter proklamasi dengan kelompok siswa yang belajar dengan pembelajaran konvensional. Adapun rata-rata hasil belajar IPS kelompok siswa yang belajar dengan pembelajaran dengan film dokumenter proklamasi yaitu 77,13 lebih besar dibandingan dengan kelompok siswa yang belajar dengan pembelajaran konvensional yaitu 64,82.

\section{Uji hipotesis ketiga}

Hipotesis 3 yang diuji dengan test of between-subjects effects yaitu $\mathrm{Ho}$, di mana kriteria menyatakan bahwa Ho ditolak apabila taraf signifikansi $F$ lebih kecil dari 0,05. Berdasarkan Tabel 4.11 diperoleh angka statistik $F$ sama dengan 22,733 dan angka sig. 0,000<0,05. Jadi hipotesis null (Ho) ditolak dan dapat disimpulkan bahwa terdapat perbedaan kemampuan berpikir kritis siswa antara kelompok siswa yang belajar dengan film dokumenter proklamasi dengan kelompok siswa yang belajar dengan pembelajaran konvensional. Adapun rata-rata kemampuan berpikir kritis kelompok siswa yang belajar dengan film dokumenter proklamasi yaitu 81,75 lebih besar dibandingan dengan kelompok siswa yang belajar dengan pembelajaran konvensional yaitu 68,35.

\section{Pembahasan \\ Hipotesis 1:}

Perbedaan Hasil Belajar IPS dan Kemampuan Berpikir Kritis Siswa Antara Kelompok Siswa yang Belajar Menggunakan Pembelajaran dengan FilmDokumenter Proklamasi dengan Kelompok Siswa yang Belajar dengan MenggunakanPembelajaranKonvensional

Adapun tujuan dari penelitian ni adalah untuk mengetahui perbedaan hasil belajar IPS dan kemampuan berpikir kritis siswa antara kelompok siswa yang belajar dengan pembelajaran film dokumenter proklamasi dengan kelompok siswa yang belajar menggunakan pembelajaran konvensional. Hasil penelitian menunjukkan bahwa terdapat perbedaan hasil belajar IPS dan kemampuan berpikir kritis siswa antara kelompok siswa yang belajar menggunakan pembelajaran dengan film dokumenter proklamasi dengan kelompok siswa yang belajar dengan menggunakan pembelajaran konvensional. Hal tersebut berdasarkan pada hasil analisis Manova yang memperoleh angka statistik $F$ sama dengan 17,315 dan angka signifikansi 0,000 kurang dari 0,05 untuk Pillai's Trace, Wilk's Lambda, Hotelling's Trace, dan Roy's Largest Root. Jadi hipotesis null $(\mathrm{Ho})$ ditolak dan $\mathrm{H} 1$ diterima. Hal ini berarti bahwa terdapat perbedaan hasil belajar IPS dan kemampuan berpikir kritis siswa antara kelompok siswa yang belajar dengan pembelajaran film dokumenter proklamasi dengan kelompok siswa yang belajar dengan pembelajaran konvensional.

\section{Hipotesis 2: Perbedaan Hasil Belajar IPS Siswa Antara Kelompok Siswa yang Belajar Menggunakan Pembelajaran dengan Film Dokumenter Proklamasi dengan Kelompok Siswa yang Belajar dengan Menggunakan Pembelajaran Konvensional}

Adapun tujuan dari penelitian ni adalah untuk mengetahui perbedaan hasil belajar IPS siswa antara kelompok siswa yang belajar dengan pembelajaran film dokumenter proklamasi dengan kelompok siswa yang belajar menggunakan pembelajaran konvensional. Hasil penelitian menunjukkan bahwa terdapat perbedaan hasil belajar IPS siswa antara kelompok siswa yangbelajarmenggunakan pembelajaran film dokumenter proklamasi dengan kelompok siswa yang belajar dengan menggunakan pembelajaran konvensional. Hal tersebut berdasarkan pada hasil analisis angka statistik $F$ sama dengan 13,060 dan angka sig. 0,001<0,05. Jadi hipotesis 
null (Ho) ditolak dan $\mathrm{H} 1$ diterima. Hal ini berarti bahwa terdapat perbedaan hasil belajar IPS siswa antara kelompok siswa yang belajar dengan pembelajaran film dokumenter proklamasi dengan kelompok siswa yang belajar dengan pembelajaran konvensional.

\section{Hipotesis 3: \\ Perbedaan Kemampuan Berpikir Kritis Siswa Antara Kelompok Siswa yang Belajar Menggunakan Pembelajaran dengan Film Dokumenter Proklamasi dengan Kelompok Siswa yang Belajar dengan Menggunakan Pembelajaran Konvensional}

Adapun tujuan dari penelitian ini adalah untuk mengetahui perbedaan kemampuan berpikir kritis siswa antara kelompok siswa yang belajar dengan pembelajaran film dokumenter proklamasi dengan kelompok siswa yang belajar menggunakan pembelajaran konvensional. Hasil penelitian menunjukkan bahwa terdapat perbedaan kemampuan berpikir kritis siswa antara kelompok siswa yang belajar menggunakan pembelajaran dengan film dokumenter proklamasi dengan kelompok siswa yang belajar dengan menggunakan pembelajaran konvensional. Hal tersebut berdasarkan pada hasil analisis angka statistik $\mathrm{F}$ sama dengan 22,733 dan angka sig. 0,000< 0,05. Jadi hipotesis null (Ho) ditolak dan $\mathrm{H} 1$ diterima. Hal ini berarti bahwa terdapat perbedaan kemampuan berpikir kritis siswa antara kelompok siswa yang belajar dengan pembelajaran film dokumenter proklamasi dengan kelompok siswa yang belajar dengan pembelajaran konvensional.

\section{Penutup}

Pada hasil analisis Manova yang memperoleh angka statistik F sama dengan 17,315 dan angka signifikansi 0,000 kurang dari 0,05 untuk Pillai's Trace, Wilk's Lambda, Hotelling's Trace, dan Roy's Largest Root. Jadi hipotesis null $(\mathrm{Ho})$ ditolak dan $\mathrm{H} 1$ diterima. Hal ini berarti bahwa terdapat perbedaan hasil belajar IPS dan kemampuan berpikir kritis siswa antara kelompok siswa yang belajar dengan pembelajaran film dokumenter proklamasi dengan kelompok siswa yang belajar dengan pembelajaran konvensional.

Hasil penelitian menunjukkan bahwa terdapat perbedaan hasil belajar IPS siswa antara kelompok siswa yang belajar menggunakan pembelajaran film dokumenter proklamasi dengan kelompok siswa yang belajar dengan menggunakan pembelajaran konvensional. Hal tersebut berdasarkan pada hasil analisis angka statistik $\mathrm{F}$ sama dengan 13,060 dan angka sig. 0,001 < 0,05. Jadi hipotesis null $(\mathrm{Ho})$ ditolak dan $\mathrm{H} 1$ diterima. Hal ini berarti bahwa terdapat perbedaan hasil belajar IPS siswa antara kelompok siswa yang belajar dengan pembelajaran film dokumenter proklamasi dengan kelompok siswa yang belajar dengan pembelajaran konvensional.

Hasil penelitian menunjukkan bahwa terdapat perbedaan kemampuan berpikir kritis siswa antara kelompok siswa yang belajar menggunakan pembelajaran dengan film dokumenter proklamasi dengan kelompok siswa yang belajar dengan menggunakan pembelajaran konvensional. Hal tersebut berdasarkan pada hasil analisis angka statistik $\mathrm{F}$ sama dengan 22,733 dan angka sig. 0,000 < 0,05. Jadi hipotesis null $(\mathrm{Ho})$ ditolak dan $\mathrm{H} 1$ diterima. Hal ini berarti bahwa terdapat perbedaan kemampuan berpikir kritis siswa antarkelompok siswa yang belajar dengan pembelajaran film dokumenter proklamasi dengan kelompok siswa yang belajar dengan pembelajaran konvensional.

Berdasarkan pembahasan di atas, maka kepada guru disarankan menggunakan penayangan film dokumenter untuk meningkatkan keterampilan berfikir kritis dan hasil belajar siswa kelas ix di smpn 2 Abiansemal, hendaknya menyediakan sarana dan prasarana yang menunjang adanya penayangan film kepada siswa. terutama guru mata pelajaran Pendidikan IPS, bahwa dalam rangka mewujudkan misi dan tujuan Pendidikan IPS, yaitu membentuk warga negara yang baik sesuai dengan nilai-nilai Pancasila dan Undang-Undang Dasar Negara Republik Indonesia tahun 1945 seperti keterampilan mengemukakan pendapat, menerima saran dan 
masukan dari orang lain, bekerja sama, saling menghormati dan menghargai perbedaan di antara mereka.Kepala sekolah sebagai supervisor dan sebagai pihak yang paling dekat dan berpengaruh untuk mengembangkan dan mengevaluasi kemampuan guru dalam melaksanakan pembelajaran diharapkan dapat menjadikan penerapan film dokumenter proklmasi pada siswa untuk memperbaiki kualitas proses dan produk pembelajaran Pendidikan IPS, dengan cara memotivasi dan memfasilitasi guru dalam menerapkan penayangan film dokumenter proklmasi pada siswa khusunya dalam pembelajran IPS agar siswa dapat lebih cepat memahami dan meninkatkan hasil belajar IPS.

Kepada para pemegang kebijakan, untuk dapat membuat sebuah formulasi metodologi pembelajaran yang relevan dan realistis dengan melibatkan para pakar dan ahli, terutama yang berkaitan dengan pengembangan model-model pembelajaran yang bernuansa kontekstual dan multikultur.Kepada para peneliti yang berniat untuk melakukan penelitian tentang penerapan penayangan film dokumenter proklmasi dan hasil belajar siswa, disarankan agar mengembangkan penelitiannya, baik dilihat dari pelibatan variable, dapat menjadi media dan sekaligus fasilitator bagi terwujudnya manusia bangsa yang memiliki kesadaran terhadap pembelajaran IPS yang tinggi serta peningkatan kualitas pendidikan.

\section{Daftar Rujukan}

Handayanto,supriono.2017.pengembangan tes berfikir kritis. jurnal: penelitian dan evaluasi pendidikan, volume21 ,no:1. hal:51-64. tersedia pada: https://journal.uny.ac.id/index.php/jpep/article/viewFile/13139/9956 .di akses pada 10 november 2018.

Resmiati,Siti Sundari. 2010.Pengaruh media film dokumenter Sejarah dan motivasi belajar dan Prestasi belajar. Tesis: https://eprints.uns.ac.id/9548/

Sudjana, Nana. 2005. Penilaian Hasil Belajar Mengajar. Bandung: Remaja Rosdakarya.

Sabri, Ahmad. 2007. Strategi Belajar Mengajar Mikro Teaching. Ciputat: Quantum Teaching.

Faturrohman, Pupuh dan Sutikno, Subri. 2007. Strategi Belajar Mengajar. Bandung: Reflika Aditama.

Lukman, maulana. 2017. Pengaruh media pembelajaran berbantuan film dokumenter pada mata pelajaran IPS. Jurnal: e jurnal katalogis, volume:5no:8.hal:9-19.tersediapada: http://jurnal.untad.ac.id/jurnal/index.php/Katalogis/article/viewFile/9679/7683 .Di akses pada 28 oktober 2018.

Johnson, E., (2006). Contextual Teaching and Learning: Menjadikan Kegiatan Belajar Mengajar Mengasyikkan dan Bermakna. Bandung: Penerbit MLC

Sitorus,syahril. 2013. Peningkatan Ketrampilan Berpikir Kritis Dan Hasil Belajar IPS. Jurnal: jurnal tematik. Volume :003. No :12 tersedia pada : http://download.garuda.ristekdikti.go.id/article.php?article $=166414 \& v a l=6082 \&$ title=Peni ngkatan\%20Ketrampilan\%20Berpikir\%20Kritis\%20Dan\%20Hasil\%20Belajar\%20IPS\% 20Melalui\%20Pendekatan\%20Inkuiri\%20Siswa\%20Kelas\%20IV\%20SD\%20Negeri\%2 0106816\%20MARINDAL\%20II\%20\%20Kecamatan\%20Patumbak

Arsyad,Azhar.2013.Media Pembelajaran. Jakarta: Raja Grafindo Persada. 